\title{
SOCIAL CAPITAL AND ECONOMIC DEVELOPMENT
}

\section{N.V. Mishenina, N.V. Oliynik}

The concept of social capital is generally associated with social and civic participation and with networks of cooperation and solidarity. But other, more abstract, concepts are also associated with social capital, such as social cohesion, trust, reciprocity, and institutional effectiveness.

The macro-approach to social capital focuses on the value of integration and social cohesion. Like the theories of institutionalism, it emphasizes a community's environmental, social, and political structures that convey values and norms (primarily trust and reciprocity), which in turn create certain conditions for social engagement and civic and economic participation. According to this conception, social capital is analyzed as a product of these structures. As a result, the more these structures instill trust and reciprocity, the more individuals will want to get involved in civic life and the more social capital will flourish. As in the case of the micro-approach, proponents of a macro-approach are interested in social capital as a collective benefit. The meso-approach is geared toward the more instrumental value of social capital. As such, it is akin to the resource mobilization theory, in that it links the concept to the potential of social networks to produce resources such as information and support.

Whereas physical capital refers to physical objects and human capital refers to the properties of individuals, social capital refers to connections among individuals - social networks and the norms of reciprocity and trustworthiness that arise from them. In that sense social capital is closely related to what some have called civic virtue. The difference is that social capital calls attention to the fact that civic virtue is most powerful when embedded in a sense network of reciprocal social relations.

Social capital focuses on networks: the relationships within and between them, and the norms which govern these relationships. Although this does not necessarily entail a specific value position on the part of those who use it as an analytic device, it has strong normative connotations, implying that trusting relationships are good for social cohesion and for economic success. However strong ties can also be dysfunctional, excluding information and reducing the capacity for innovation.

The key distinction between human and social capital is that the former focuses on individual agents, and the latter on relationships between them and the networks they form. In an economic context, the inclusion of social capital draws attention to the obvious, but often underregarded fact, that individuals and their human capital are not discrete entities who exist separately from the rest of the organisation, or from other social units.

There is a need to devote greater attention to social capital's determinants. Social capital is viewed here as the result of investment decisions taken by individuals. Those investments bring both market and non-market returns. A simple social capital investment model is presented, suggesting that individuals are more likely to invest in social capital when they are likely to be in their communities for some time. Not surprisingly, homeownership increases the level of investment in social capital. The model also suggests that, over a lifetime, people first build up stocks of social capital and then let those stocks decline. Two other influences, not present in the model, are clearly very important for social capital. First, there is a very strong relationship between years of schooling and social capital. Second, community homogeneity strongly increases social capital investment.

The best way for an economist to think of community level social capital is as the set of social resources of a community that increases the welfare of that community. These social resources, of course, include norms and networks. Economists tend to think that these social resources have value because they solve common economic problems. For example, better social connections can help to solve the free-rider problem in providing public goods, or they can create trust between individuals in the absence of explicit contracts (hence the frequent use of trust survey questions to capture social capital). 
There are two main form of social capital: bonding social capital and bridging social capital. The former refers to the value assigned to social networks between homogeneous groups of people and the latter to that of social networks between socially heterogeneous groups. Typical examples are that criminal gangs create bonding social capital, while choirs and bowling clubs create bridging social capital. Bridging social capital is argued to have a host of other benefits for societies, governments, individuals, and communities; likes to note that joining an organization cuts in half an individual's chance of dying within the next year.

The World Bank has brought together a range of statistics to make the case for the social and economic benefits of social capital. For example they argue that there is evidence that schools are more effective when parents and local citizens are actively involved. Teachers are more committed, students achieve higher test scores, and better use is made of school facilities in those communities where parents and citizens take an active interest in children's educational well-being

The distinction is useful in highlighting how social capital may not always be beneficial for society as a whole (though it is always an asset for those individuals and groups involved).

Horizontal networks of individual citizens and groups that enhance community productivity and cohesion are said to be positive social capital assets whereas self-serving exclusive gangs and hierarchical patronage systems that operate at cross purposes to societal interests can be thought of as negative social capital burdens on society.

So, the necessity of social capital in the conditions of the transformation of social-economic relations into the market system are equal or greater importance than economic factors such as levels of inward investment, new floorspace provided, or even formal training qualifications. In other words, social capital and social development is as important to economic development as economic capital.

They are closely connected with economical and political mechanism functioning in the country. 